\title{
MANEJO DA ADUBAÇÃO POTÁSSICA NA CULTURA DA CANA-DE-AÇÚCAR ${ }^{(1)}$
}

\author{
Rafael Otto ${ }^{(2)}$, Godofredo Cesar Vitti ${ }^{(3)}$ \& Pedro Henrique de \\ Cerqueira Luz ${ }^{(4)}$
}

\begin{abstract}
RESUMO
O Brasil é o maior produtor mundial de cana-de-açúcar e, devido à crescente demanda por fontes renováveis de energia, a área cultivada encontra-se em expansão. Regularmente, a cultura é plantada em solos com baixos teores de nutrientes, o que pode limitar sua produtividade. A adubação potássica da canade-açúcar é feita basicamente no sulco de plantio, o que pode comprometer a eficiência de utilização desse nutriente devido a possíveis perdas por lixiviação ou salinidade às raízes das plantas. $O$ objetivo deste estudo foi avaliar produtividade de colmos e atributos tecnológicos da cana-de-açúcar em função de doses e modos de aplicação de $K$. O experimento foi conduzido em um Latossolo Vermelho distrófico durante o ciclo de cana-planta, com o cultivar SP90 3414, em esquema fatorial $2 \times 4$, sendo dois modos de aplicação (100\% no plantio e $50 \%$ no plantio + $50 \%$ em cobertura) e quatro doses de $\mathrm{K}\left(0,100,150\right.$ e $\left.200 \mathrm{~kg} \mathrm{ha}^{-1} \mathrm{de}_{2} \mathrm{O}\right)$, com quatro repetições. Aos nove meses após o plantio, foram avaliados a altura das plantas e o perfilhamento e, na colheita, a produtividade de colmos e os atributos tecnológicos da cana-de-açúcar. As doses de K aumentaram o crescimento em altura e o perfilhamento da cana-de-açúcar, para os dois modos de aplicação; a produtividade de colmos e de açúcar aumentou com as doses de $\mathrm{K}$ até um ponto de máximo de, aproximadamente, $160 \mathrm{~kg} \mathrm{ha}^{-1}$ de $\mathrm{K}_{2} \mathrm{O}$; e a produtividade máxima estimada de cerca de $160 \mathrm{t} \mathrm{ha}^{-1}$ foi obtida com 130 e $150 \mathrm{~kg} \mathrm{ha}^{-1} \mathrm{de}_{2} \mathrm{O}$, para a aplicação parcelada e única do fertilizante, respectivamente.
\end{abstract}

Termos de indexação: Saccharum spp., cana-planta, cobertura, cloreto de potássio, produtividade.

\footnotetext{
(1) Recebido para publicação em fevereiro de 2009 e aprovado em maio de 2010.

${ }^{(2)}$ Doutorando do Programa de Pós-Graduação em Solos e Nutrição de Plantas, Escola Superior de Agricultura "Luiz de Queiroz" - ESALQ/USP. Bolsista FAPESP. Laboratório de Isótopos Estáveis, CENA/USP. Av. Centenário 303, Bairro São Dimas, Caixa Postal 96, CEP 13400-970 Piracicaba (SP). E-mail: rotto@esalq.usp.br

(3) Professor do Departamento de Ciência do Solo, ESALQ/USP. Av. Pádua Dias 11, Caixa Postal 09, CEP 13418-900 Piracicaba (SP). E-mail: gcvitti@esalq.usp.br

(4) Professor do Departamento de Agrárias, Faculdade de Zootecnia e Engenharia de Alimentos - FZEA/USP. Rua Duque de Caxias Norte, 225, Campus da USP, CEP 13635-900, Pirassununga/SP. E-mail: phcerluz@usp.br
} 


\title{
SUMMARY: POTASSIUM FERTILIZER MANAGEMENT FOR SUGAR CANE
}

\begin{abstract}
Brazil is the largest sugar cane producer in the world and, due to the increasing interest in renewable energy sources, the cultivated area is expanding. Sugar cane is usually planted in soil with low nutrient levels, which can limit the yield. In sugar cane, potassium is basically applied in the furrow, which can decrease the K use efficiency due to leaching or salinizaton to plant roots. The goal of this study was to evaluate stalk yield and technological properties of sugar cane as related to K application rates and methods. The experiment was carried out in an Oxissol during a plant cane cycle of variety SP90 3414, in a $2 \times 4$ split-plot design, with two Kapplication methods $(\mathrm{a}-100 \%$ in the planting and $\mathrm{b}-50 \%$ in the planting and $50 \%$ sidedressed after six months) and four K rates (control, 100, 150 and $200 \mathrm{~kg} \mathrm{ha}^{-1} \mathrm{~K}_{2} \mathrm{O}$ ), with four replications. Nine months after planting, plant height and shoot number were evaluated and, in the harvest, stalk yield and technological properties were obtained. The K rates increased sugarcane growth and shoot number in both application methods; the stalks and sugar yield increased with potassium rates, reaching a peak at a dose of around $160 \mathrm{~kg} \mathrm{ha}^{-1} \mathrm{~K}_{2} \mathrm{O}$; the estimated maximum yield (160 $\left.\mathrm{t} \mathrm{ha}^{-1}\right)$ was obtained with $130 \mathrm{~kg} \mathrm{ha}^{-1}$ of $\mathrm{K}_{2} \mathrm{O}$ in split application (in the furrow and side-dressed after six months) and with $150 \mathrm{~kg} \mathrm{ha}^{-1}$ of $\mathrm{K}_{2} \mathrm{O}$ when the fertilizer was applied in the furrow only.
\end{abstract}

Index terms: Saccharum spp., plant cane, side-dressed application, potassium chloride, stalk yield.

\section{INTRODUÇÃO}

O Brasil é o maior produtor mundial de cana-deaçúcar, com produção de $514 \mathrm{Mt}$ em 2007, seguido da Índia (356 Mt) e da China (106 Mt), segundo dados do Ministério da Agricultura, Pecuária e Abastecimento (Brasil, 2009). A área cultivada com cana-de-açúcar no Brasil atingiu em 2009 aproximadamente 8,7 Mha $\mathrm{e}$, em relação às culturas agrícolas, é inferior somente à área de soja (21,7 Mha) e milho (13,7 Mha), conforme o Instituto Brasileiro de Geografia e Estatística (IBGE, 2009). Além disso, compromissos internacionais para utilização de fontes renováveis de energia e redução das emissões de gases do efeito estufa deverão promover, nos próximos anos, aumento considerável na área plantada com cana-de-açúcar no Brasil visando à produção de etanol.

A cultura da cana-de-açúcar consome aproximadamente $13 \%$ do total de fertilizantes utilizados anualmente no Brasil, com um total de 2,9 Mt, inferior somente ao consumido pelas culturas de soja $(7,4 \mathrm{Mt})$ e milho (4,4 Mt) (ANDA, 2008). O principal fertilizante com K utilizado no Brasil é o $\mathrm{KCl}$, que contém aproximadamente $60 \%$ de $\mathrm{K}_{2} \mathrm{O}$.

$\mathrm{O} \mathrm{K}$ desempenha diversas funções metabólicas e estruturais na planta. Nos solos da região tropical, os teores de K normalmente são baixos (normalmente inferiores a $1,5 \mathrm{mmol}_{\mathrm{c}} \mathrm{dm}^{-3}$ ), tornando necessária a complementação desse nutriente com fertilizantes para possibilitar produtividades sustentáveis. $\mathrm{OK}$, seguido pelo N, é o nutriente mais absorvido pela cana-deaçúcar. Para cada $100 \mathrm{t} \mathrm{ha}^{-1}$ de colmos, são exportados cerca de $150 \mathrm{~kg} \mathrm{ha}^{-1}$ de $\mathrm{K}_{2} \mathrm{O}$ (Malavolta, 1982), embora em solos com teores elevados de $\mathrm{K}$ a exportação pelos colmos possa atingir $285 \mathrm{~kg} \mathrm{ha}^{-1}$ de $\mathrm{K}_{2} \mathrm{O}$ (Franco et al., 2008).
O K do solo é formado pelo K da solução, K trocável, K não trocável (fixado) e o K estrutural, e o suprimento de K para as plantas advém da solução e dos sítios de troca dos coloides do solo, que estão em equilíbrio com o K não trocável e com o K estrutural dos minerais (Sparks \& Huang, 1985). O teor trocável é a principal fonte de reposição do K para a solução (Raij, 1991), o qual, por sua vez, pode ser absorvido pelas plantas, adsorvido às cargas negativas do solo ou perdido por lixiviação. Dessa maneira, recomenda-se realizar a aplicação desse nutriente conforme as plantas se desenvolvem, visando reduzir as perdas no sistema solo-planta e aumentar a eficiência de utilização desse nutriente. Entretanto, no setor sucroalcooleiro a aplicação do K normalmente é feita de uma única vez, na ocasião do plantio, com dose que varia de 80 a $140 \mathrm{~kg} \mathrm{ha}^{-1}$ de $\mathrm{K}_{2} \mathrm{O}$ (Lana et al., 2004).

O K adicionado via adubação potássica, assim como aquele disponibilizado da palha que permanece sobre o solo, pode ser intensamente lixiviado no perfil do solo, dependendo da quantidade de chuva, da dose de nutriente e da textura do solo, entre outros fatores (Rosolem et al., 2006). Rosolem \& Nakagawa (2001) observaram aumento na lixiviação de $\mathrm{K}$ no perfil de um solo de textura média quando foram aplicadas doses acima de $80 \mathrm{~kg} \mathrm{ha}^{-1}$ de $\mathrm{K}_{2} \mathrm{O}$ por ano, independentemente do modo de aplicação do fertilizante. Além de favorecer a lixiviação, o K aplicado em doses elevadas e de uma única vez pode causar a salinização da região que recebe o fertilizante, podendo causar toxidez às raízes das plantas. Souza et al. (2007) verificaram redução do comprimento de raízes do algodão quando o fertilizante foi aplicado ao lado das sementes, e Alvarez \& Freire (1962) observaram que plantas de cana-de-açúcar que receberam doses mais elevadas de K $\left(270 \mathrm{~kg} \mathrm{ha}^{-1}\right.$ de 
$\mathrm{K}_{2} \mathrm{O}$ ), aplicadas de uma única vez no plantio, apresentaram sintomas atribuídos ao excesso do nutriente.

No Brasil, praticamente o primeiro trabalho de calibração do K trocável no solo para cana-de-açúcar foi realizado por Raij (1974), quando foi determinado o nível crítico de $2,1 \mathrm{mmol}_{\mathrm{c}} \mathrm{dm}^{-3} \mathrm{de} \mathrm{K}$. Posteriormente, Orlando Filho et al. (1981) obtiveram nível crítico de 2,3 $\mathrm{mmol}_{\mathrm{c}} \mathrm{dm}^{-3}$ de K, enquanto Rodella et al. (1983), utilizando maior número de dados experimentais, sugeriram o nível crítico de $2,0 \mathrm{mmol}_{\mathrm{c}} \mathrm{dm}^{-3}$ no solo para produção relativa de $90 \%$. Com base na curva de calibração obtida neste trabalho, formulou-se a recomendação de adubação potássica adotada pelo Planalsucar na região Centro-Sul do Brasil, com doses de $\mathrm{K}_{2} \mathrm{O}$ que variavam de 0 a $200 \mathrm{~kg} \mathrm{ha}^{-1}$. Atualmente, a adubação potássica para o plantio da cana-de-açúcar no Estado de São Paulo baseia-se nas classes de teores de $\mathrm{K}$ no solo e com doses que variam de 0 a $200 \mathrm{~kg} \mathrm{ha}^{-1}$ de $\mathrm{K}_{2} \mathrm{O}$, sendo o parcelamento indicado somente em solos de textura arenosa ou média (Spironello et al., 1997).

Diversos trabalhos avaliaram, nas mais diversas condições de clima, solo e cultivares, a produtividade da cana-de-açúcar em função de doses de K, permitindo inclusive gerar curvas de calibração com grande número de observações. Como exemplo, Reis Junior (2001) reuniu 106 experimentos com adubação potássica em cana-de-açúcar. No entanto, poucos foram os trabalhos que avaliaram os modos de aplicação desse nutriente na produtividade da canade-açúcar, limitando-se aos de Alvarez \& Freire (1962), Albuquerque \& Marinho (1982), Casagrande et al. (1983) e Lana et al. (2004), porém com cultivares mais antigos. Além disso, com o advento da colheita da cana sem despalha a fogo ("cana-crua"), a reciclagem do K da palha que permanece sobre o solo (Oliveira et al., 1999) pode diminuir a resposta da cana ao fertilizante potássico.

O fracionamento de doses elevadas de K é conveniente porque, além da possibilidade de reduzir, em certos solos, as perdas por lixiviação, contribui para evitar excessiva concentração de sais nas proximidades dos toletes (Alvarez \& Freire, 1962). Esses autores comentam que o êxito do parcelamento da adubação potássica é atribuído ao fato de que boa parte do sistema radicular da cana localiza-se nas camadas superficiais do solo.

Trabalhando com doses de até $200 \mathrm{~kg} \mathrm{ha}^{-1} \mathrm{de}_{2} \mathrm{O}$ em um Latossolo Vermelho distroférrico arenoso, com teores muito baixos de K trocável, Lana et al. (2004) observaram efeito linear na produtividade da canade-açúcar e nos teores de pol \% cana. Verificaram também efeito para o parcelamento da dose de $120 \mathrm{~kg} \mathrm{ha}^{-1}$ na produtividade de colmos, associando o efeito à lixiviação do K quando aplicado unicamente no plantio. Já Albuquerque \& Marinho (1982) obtiveram efeito para o parcelamento do $\mathrm{K}$ em um Latossolo Vermelho-Amarelo textura arenosa, o que não foi observado em um Argissolo Vermelho-Amarelo.

Este trabalho objetivou avaliar perfilhamento, produtividade de colmos e atributos tecnológicos da cana-de-açúcar em função de doses e modos de aplicação do fertilizante potássico.

\section{MATERIAL E MÉTODOS}

O experimento foi conduzido em área cultivada com cana-de-açúcar pela Usina Santa Helena, do Grupo Cosan, no município de Piracicaba/SP. O cultivar utilizado foi o SP90 3414.

O solo da área experimental é um Latossolo Vermelho distrófico textura média (Quadro 1). A amostragem de solo foi realizada cerca de 20 dias após a aplicação do calcário e do gesso e antes da aplicação do superfosfato simples. O pequeno intervalo de tempo entre a aplicação e a amostragem de solo não permitiu uma reação completa dos corretivos com o solo, evidenciada pelo baixo $\mathrm{pH}$ e baixa saturação por bases e elevado teor de $\mathrm{Al}^{3+}$ (Quadro 1), porém as doses de corretivos utilizadas certamente promoveram a

Quadro 1. Atributos químicos e físicos do solo da área em estudo em duas profundidades, antes da implantação do experimento ${ }^{(1)}$

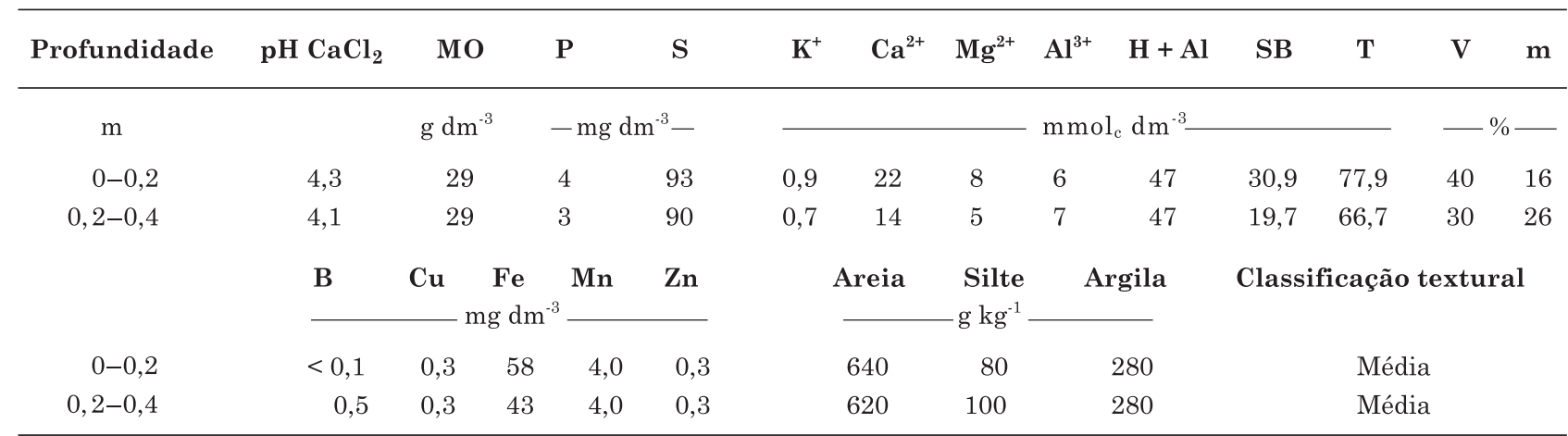

(1) Extratores: P, K, Ca e Mg: resina trocadora de íons (Raij et al., 2001); Al: KCl 1 N; S: acetato de amônio 0,5 N em ácido acético 0,25 N (Vitti, 1989). Extratores: Cu, Fe, Mn e Zn: DTPA; B: água quente (Raij et al., 2001). 
correção da acidez do solo, levando em consideração o longo ciclo de crescimento da cana-planta.

O delineamento experimental foi em blocos casualizados, em esquema fatorial $2 \times 4$, sendo duas épocas de aplicação do fertilizante: $a$ - $100 \%$ no plantio e $b$ - $50 \%$ no plantio e $50 \%$ em cobertura, e quatro doses de K na forma de KCl: 0, 100, 150 e $200 \mathrm{~kg}^{\mathrm{ha}}{ }^{-1}$ de $\mathrm{K}_{2} \mathrm{O}$, com quatro repetições. As parcelas foram constituídas de sete linhas de $10 \mathrm{~m}$ de comprimento, espaçadas de 1,40 m (98 $\mathrm{m}^{2}$ por parcela), com as avaliações realizadas nas cinco linhas centrais (área útil de $70 \mathrm{~m}^{2}$ ).

O plantio foi realizado em 12 de março de 2005 . $\mathrm{Na}$ fase de preparo do solo foram aplicadas, em área total e com posterior incorporação, 2,8 t ha $\mathrm{a}^{-1}$ de calcário dolomítico, com PRNT de $80 \%$, visando elevar a saturação por bases para $60 \%$, conforme Spironello et al. (1997), 1,9 t ha-1 de gesso agrícola e $525 \mathrm{~kg} \mathrm{ha}^{-1}$ de superfosfato simples. No plantio foram aplicados, via fertilizante mineral, $54 \mathrm{~kg} \mathrm{ha}^{-1}$ de $\mathrm{Ne} 135 \mathrm{~kg}^{\mathrm{ha}}{ }^{-1}$ de $\mathrm{P}_{2} \mathrm{O}_{5}$, além dos inseticidas carbofuran $\left(7 \mathrm{~L} \mathrm{ha}^{-1}\right.$ do produto comercial Furadan $350 \mathrm{G}^{\circledR}$ ) e fipronil $\left(0,25 \mathrm{~kg} \mathrm{ha}^{-1}\right.$ do produto comercial Regent $\left.800 \mathrm{WG}^{\circledR}\right)$. Os sulcos foram abertos com cerca de $0,3 \mathrm{~m}$ de profundidade, com distância entre sulcos de 1,40 m, e, após a distribuição das mudas (cerca de 15 gemas viáveis por metro), estas foram cobertas com uma camada de $0,1 \mathrm{~m}$ de solo. Nos tratamentos correspondentes, o $\mathrm{K}$ foi aplicado na forma de $\mathrm{KCl}$ no fundo do sulco, juntamente com o $\mathrm{N}$ e o $\mathrm{P}$, antes da deposição das mudas. Em setembro de 2005 (seis meses após o plantio) foi realizada aplicação do K em cobertura nos tratamentos correspondentes. A fonte utilizada foi o $\mathrm{KCl}$, e a aplicação foi realizada manualmente, ao lado das linhas da cana, sem incorporação.

Aos seis meses após o plantio e antes da adubação de cobertura, foi realizada coleta de folhas das plantas para avaliação do estado nutricional. Foram coletadas 15 folhas +3 por parcela, utilizando somente o terço médio e descartando-se a nervura central, seguindo o procedimento de coleta e análise descrito por Malavolta et al. (1997).

Aos nove meses após o plantio (13/12/2005), em cada parcela, foi realizada contagem do número de perfilhos em $2 \mathrm{~m}$ de linha e em três locais das linhas que constituem a área útil da parcela. Nessa data também foi realizada a medição da altura de cinco plantas por parcela, sendo a altura correspondente à distância entre o solo e o ponto mais alto da folha mais nova da planta (folha bandeira).

A colheita foi realizada manualmente após a queima acidental do canavial, em 25 de julho de 2006, completando um ciclo de 16 meses. Foram colhidas as sete linhas de cana de cada parcela, porém foi considerada somente a massa de colmos das cinco linhas centrais da parcela, desconsiderando-se as linhas 1 e 7. Para a pesagem dos colmos obtidos em cada parcela, foi utilizado um dinamômetro acoplado à garra de uma carregadora de cana. No mesmo dia da colheita, foram amostradas 10 canas seguidas em uma mesma linha dentro da parcela, com posterior retirada da palha e do ponteiro, para realização da análise tecnológica (pol, brix, fibra, pureza), segundo procedimentos descritos em Fernandes (2003).

Foi realizada análise de variância e, para os atributos com valor de $\mathrm{F}$ significativo, procedeu-se à análise de regressão a fim de avaliar o efeito dos fatores do estudo nas variáveis dependentes.

\section{RESULTADOS E DISCUSSÃO}

Aos seis meses após o plantio, o teor de K nas folhas das plantas que receberam a dose completa de K no sulco de plantio foram superiores ao teor encontrado nas folhas das plantas que receberam somente metade da dose no plantio (Figura 1). Nessa ocasião, ainda não havia sido realizada a adubação de cobertura nos tratamentos com aplicação parcelada. O teor de K nas folhas das plantas que receberam somente metade da dose no sulco de plantio ficou muito próximo daqueles das plantas que não receberam o fertilizante potássico (controle). Embora em todos os tratamentos o teor de $\mathrm{K}$ nas folhas tenha se mantido dentro da faixa de suficiência (10 a $16 \mathrm{~g} \mathrm{~kg}^{-1}$, segundo Spironello et al., 1997), no tratamento controle e nos tratamentos que receberam 50 e $75 \mathrm{~kg} \mathrm{ha}^{-1}$ de $\mathrm{K}_{2} \mathrm{O}$ no plantio, os teores foram próximos ao limite inferior da faixa de suficiência e inferiores aos teores encontrados nas folhas das plantas que receberam 100, $150 \mathrm{e} 200 \mathrm{~kg} \mathrm{ha}^{-1} \mathrm{de}$ $\mathrm{K}_{2} \mathrm{O}$ no plantio. Isso indica que a aplicação de somente metade da dose de $\mathrm{K}$ no sulco de plantio, em solo com baixo teor de K trocável (Quadro 1), pode submeter as plantas à deficiência desse nutriente. Os teores dos demais nutrientes estavam dentro dos níveis considerados adequados para a cultura da cana-de-

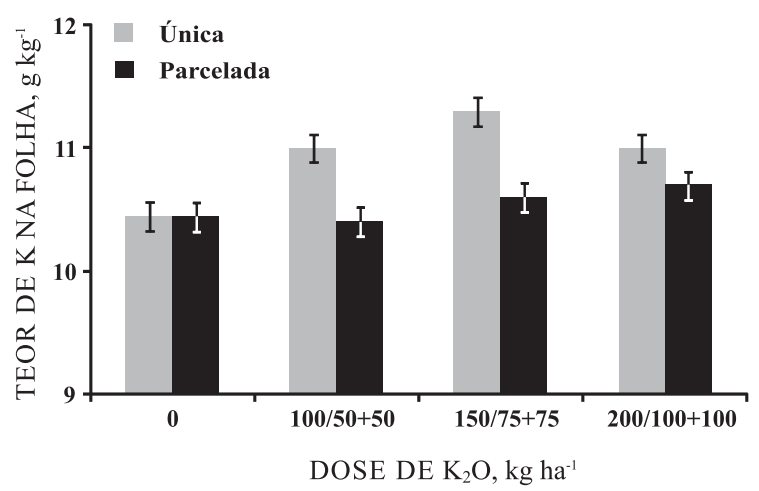

Figura 1. Teor de potássio na folha +3 da cana-deaçúcar aos seis meses após o plantio (antes da adubação de cobertura), em função das doses aplicadas inteiramente no plantio (Única) e metade no plantio e metade em cobertura (Parcelada). As barras representam o erropadrão da média para $n=4$. 
açúcar (dados não apresentados). A complementação da dose de K em cobertura, três meses após a análise foliar, nos tratamentos que receberam 50 e $75 \mathrm{~kg} \mathrm{ha}^{-1}$ de $\mathrm{K}_{2} \mathrm{O}$ no plantio, evitou que as plantas apresentassem deficiência desse nutriente, tendo em vista que apresentaram mesma altura (Figura 2), perfilhamento (Figura 3) e produtividade de colmos (Figura 4) das plantas que receberam a dose completa de $\mathrm{K}$ no sulco de plantio.

A adubação potássica favoreceu o crescimento da cana-de-açúcar, tanto para a aplicação única no sulco de plantio quanto para a aplicação parcelada, em avaliação realizada aos nove meses após a adubação potássica de plantio e três meses após a de cobertura (Figura 2). Orlando Filho et al. (1993) obtiveram resultados semelhantes, com a deficiência de $\mathrm{K}$ causando diminuição da altura dos colmos e o parcelamento do K não apresentando diferença em relação à aplicação única no sulco de plantio. Entretanto, com o aumento da dose de $\mathrm{K}$ a partir de $150 \mathrm{~kg} \mathrm{ha}^{-1}$ de $\mathrm{K}_{2} \mathrm{O}$, houve diminuição na altura das plantas.

À medida que se aumentou a dose de K, a modalidade de aplicação do fertilizante alterou o padrão de perfilhamento da cana-de-açúcar (Figura 3). Para a aplicação única no sulco de plantio, o número de perfilhos aumentou até a dose aproximada de $130 \mathrm{~kg} \mathrm{ha}^{-1}$ de $\mathrm{K}_{2} \mathrm{O}$, a partir da qual ocorreu decréscimo no perfilhamento da cana-de-açúcar, possivelmente devido à elevada quantidade de sais adicionados no sulco de plantio. Quanto à aplicação parcelada, não se observou decréscimo do perfilhamento com o aumento das doses, possivelmente por ter sido aplicada somente metade da dose no sulco de plantio e o restante em cobertura, três meses antes da avaliação do perfilhamento. Embora as doses de K tenham alterado o perfilhamento da cana-de-açúcar neste trabalho, Casagrande et al. (1983) e Orlando Filho et al. (1993) não observaram efeito das doses de K no perfilhamento da cana-de-açúcar em seus trabalhos.

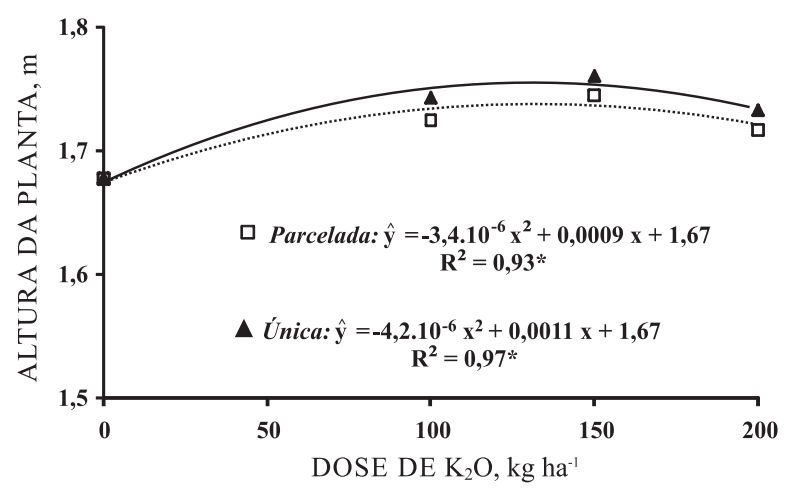

Figura 2. Altura das plantas de cana-de-açúcar aos nove meses após o plantio, em função das doses e modos de aplicação de potássio. *: significativo a $5 \%$.

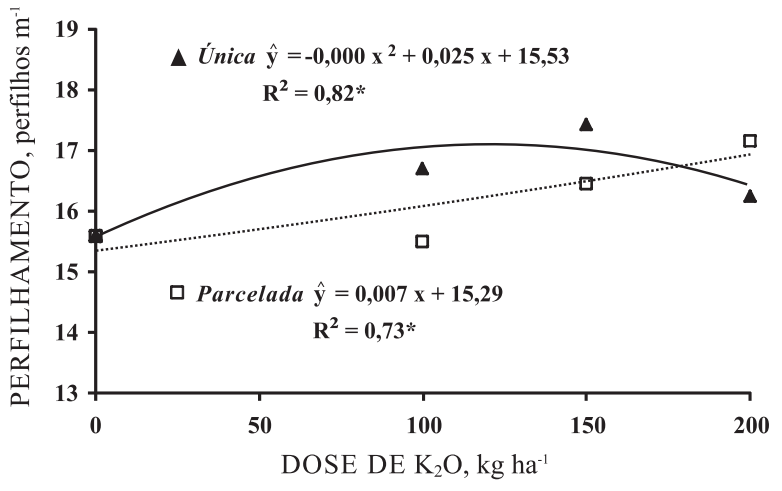

Figura 3. Perfilhamento da cana-de-açúcar aos nove meses após o plantio, em função das doses e modos de aplicação de potássio. *:significativo a $10 \%$.

Para as doses intermediárias, de 100 e $150 \mathrm{~kg} \mathrm{ha}^{-1}$ de $\mathrm{K}_{2} \mathrm{O}$, a aplicação única no sulco de plantio resultou em maior número de perfilhos em relação ao parcelamento. Entretanto, o tratamento que recebeu $50 \mathrm{~kg} \mathrm{ha}^{-1}$ de $\mathrm{K}_{2} \mathrm{O}$ no plantio e apresentou baixo perfilhamento (Figura 3) obteve produtividade até mesmo superior à do tratamento que recebeu $100 \mathrm{~kg} \mathrm{ha}^{-1}$ de $\mathrm{K}_{2} \mathrm{O}$ no sulco (Figura 4) e apresentou melhor perfilhamento (Figura 3). Isso pode estar relacionado ao fato de que, a partir dessa fase, iniciase a morte e senescência de parte dos perfilhos devido à competição intraespecífica por luz e nutrientes, indicando que a produtividade pode não ser beneficiada por um perfilhamento excessivo.

Em relação à produtividade de colmos, não houve efeito entre os modos de aplicação do fertilizante nem interação entre modos de aplicação e doses, porém houve efeito significativo para as doses de $K(p<0,01)$. Essas doses exerceram efeito quadrático na produtividade de colmos nos dois modos de aplicação do fertilizante (Figura 4), confirmando o efeito favorável do K na produtividade da cana-de-açúcar (Orlando Filho et al., 1993; Lana et al., 2004; Rossetto et al., 2004). O acréscimo de produtividade foi significativo e da ordem de $18 \mathrm{t} \mathrm{ha}^{-1}$ entre a dose que proporcionou a maior produtividade e o tratamento controle. Enquanto neste trabalho observou-se efeito quadrático das doses de K na produtividade de colmos, outros autores observaram efeito linear do K na produtividade da cana. Lana et al. (2004) obtiveram efeito linear até a dose de $200 \mathrm{~kg} \mathrm{ha}{ }^{-1}$ de $\mathrm{K}_{2} \mathrm{O}$ em um Latossolo Vermelho distrófico arenoso com teor muito baixo de $\mathrm{K}$ no solo $\left(0,1 \mathrm{mmol}_{\mathrm{c}} \mathrm{dm}^{-1}\right.$ de $\mathrm{K}$ na camada de 0 a $25 \mathrm{~cm}$ ), o que pode explicar o elevado efeito das doses de K na produtividade. Rossetto et al. (2004) obtiveram efeito linear ao $\mathrm{K}$ em três de seis experimentos em cana-planta, porém com parcelamento da maior dose $\left(200 \mathrm{~kg} \mathrm{ha}^{-1} \mathrm{de}_{2} \mathrm{O}\right)$, não obtendo queda de produtividade com essa dose em nenhuma das áreas. Por outro lado, neste trabalho, a dose de $200 \mathrm{~kg} \mathrm{ha}^{-1}$ de $\mathrm{K}_{2} \mathrm{O}$ causou decréscimo na produtividade de colmos, em relação às doses de $100 \mathrm{e}$ 


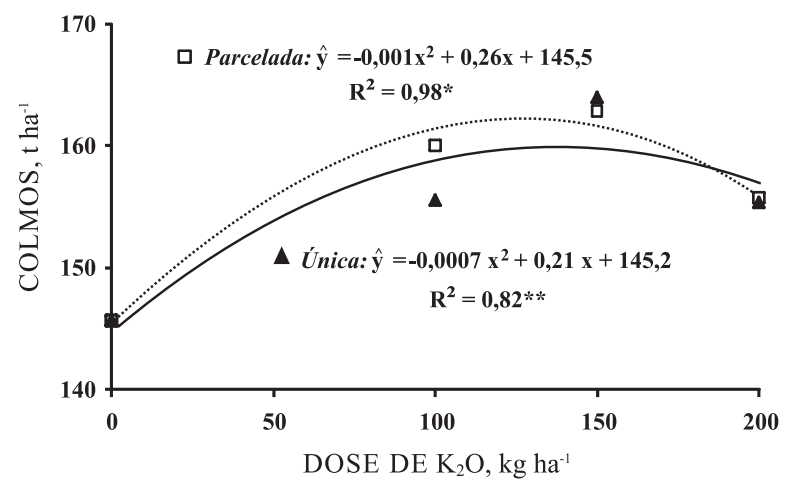

Figura 4. Produtividade da cana-de-açúcar $\left(\mathrm{t} \mathrm{ha}^{-1}\right)$, em função dos modos e doses de aplicação de potássio. ** e *: significativo a 1 e $5 \%$, respectivamente.

$150 \mathrm{~kg} \mathrm{ha}{ }^{-1}$ de $\mathrm{K}_{2} \mathrm{O}$, para os dois modos de aplicação do fertilizante (Figura 4). Isso indica que, nessa condição de solo, houve absorção em excesso de $\mathrm{K}$, que causou toxidez às plantas. As diferenças encontradas nesses trabalhos, em relação à existência ou não de toxidez de K para doses elevadas do nutriente, estão relacionadas às condições específicas de cada experimento em relação ao solo, ao clima e às características da planta. Sabe-se que as plantas conseguem muitas vezes absorver o nutriente de camadas mais profundas do solo, assim como de formas não trocáveis, como dos minerais primários e secundários (Raij, 1991). Além disso, em solos com maior CTC o K em solução pode ser adsorvido às cargas negativas do solo e tornar-se menos disponível às plantas em relação a solos com baixa CTC. Esses são alguns fatores que podem interferir na relação soloplanta-nutriente, alterando a resposta da cana-deaçúcar à fertilização potássica.

Derivando as funções dadas pela equação que descreve as curvas e igualando a função a zero, obtémse a dose de $\mathrm{K}$ que permite atingir a produtividade máxima estimada. Para a aplicação parcelada, essa dose foi de $130 \mathrm{~kg} \mathrm{ha}^{-1}$ de $\mathrm{K}_{2} \mathrm{O}$, enquanto para a aplicação única foi de $150 \mathrm{~kg} \mathrm{ha}^{-1} \mathrm{de} \mathrm{K}_{2} \mathrm{O}$. Substituindo esse valor na função que descreve a curva, obtém-se a produtividade máxima estimada para cada modo de aplicação do fertilizante potássico. Dessa forma, os dados permitiram estimar a produtividade máxima, que foi de 162,4 e 161,0 t ha ${ }^{-1}$ de colmos para a aplicação parcelada e única, respectivamente.

A adubação potássica de uma única vez no sulco de plantio pode ter favorecido a lixiviação do $\mathrm{K}$, uma vez que no início do ciclo o sistema radicular é pouco desenvolvido. Além disso, problemas com lixiviação de K são mais intensos em solos arenosos, com baixa CTC, como o deste estudo. Werle et al. (2008) observaram que a lixiviação foi mais intensa no solo mais arenoso, decrescendo com o tempo, enquanto no solo argiloso as perdas foram mais constantes. Nesse sentido, deve-se considerar que podem ocorrer perdas apreciáveis de K por lixiviação em áreas cultivadas com cana-de-açúcar. Em um Latossolo de textura média cultivado com cana-de-açúcar no ciclo de canaplanta, as perdas de $\mathrm{K}$ por lixiviação, provenientes do solo e do fertilizante, foram de $80 \mathrm{~kg} \mathrm{ha}^{-1}$ de $\mathrm{K}_{2} \mathrm{O}$ (Ghiberto et al., 2009a), com aplicação de $120 \mathrm{~kg} \mathrm{ha}^{-1}$ de $\mathrm{K}_{2} \mathrm{O}$ no sulco de plantio. Na cana-soca dessa mesma área foram aplicados $150 \mathrm{~kg} \mathrm{ha}^{-1} \mathrm{de}_{2} \mathrm{O}$ na soqueira, e as perdas por lixiviação, tanto provenientes do solo quanto do fertilizante, variaram de 32 a $65 \mathrm{~kg} \mathrm{ha}^{-1} \mathrm{de}$ $\mathrm{K}_{2} \mathrm{O}$ (Ghiberto, 2009b).

Provavelmente ocorreu perda por lixiviação para todas as doses de $\mathrm{K}$ aplicadas no sulco de plantio. Entretanto, somente para a dose de $100 \mathrm{~kg} \mathrm{ha}^{-1}$ de $\mathrm{K}_{2} \mathrm{O}$, aplicada de uma única vez, a produtividade foi inferior em relação à aplicação parcelada do $\mathrm{K}$ (Figura 4). Para a dose de $150 \mathrm{~kg} \mathrm{ha}^{-1}$ de $\mathrm{K}_{2} \mathrm{O}$ a produtividade foi semelhante entre a aplicação única ou parcelada, indicando que, mesmo perdendo parte dessa quantidade por lixiviação quando o fertilizante foi aplicado totalmente no sulco, a quantidade que restou na zona de absorção radicular foi suficiente para fornecer o nutriente às plantas. Ademais, o parcelamento da adubação, com aplicação superficial após seis meses do plantio, provavelmente promoveu maior absorção de K pela cana-de-açúcar, tendo em vista que a maior parte das raízes responsáveis pela absorção dos nutrientes localiza-se na camada superficial do solo (Inforzato \& Alvarez, 1957; Faroni, 2004; Otto, 2009).

Enquanto Casagrande et al. (1983) não observaram efeito do parcelamento da adubação potássica na produtividade de colmos, Lana et al. (2004) obtiveram aumento de produtividade com o parcelamento da dose de $120 \mathrm{~kg} \mathrm{ha}^{-1}$ de $\mathrm{K}_{2} \mathrm{O}$ em relação à aplicação única no sulco. Além disso, Orlando Filho et al. (1993) também observaram maior produtividade com o parcelamento do K. Observando detalhadamente os dados obtidos por Casagrande et al. (1983), houve tendência de aumento da produtividade com o parcelamento da adubação potássica no solo com baixa CTC (Neossolo Quartzarênico), enquanto nos solos com alta CTC (Argissolo e Latossolos) houve tendência de diminuição da produtividade com o parcelamento. Essa última constatação pode estar relacionada ao fato de que, quanto maior o poder-tampão do solo em $\mathrm{K}$, menor é a absorção de K pela planta e, nesses solos, há necessidade de maior quantidade desse elemento para satisfazer a demanda da planta (Wietholter, 2007). Assim, nos solos de elevada CTC, a menor dose de $\mathrm{K}$ aplicada no sulco pode ter limitado a produtividade, mesmo com o parcelamento do restante da dose em cobertura, que não foi capaz de satisfazer a demanda das plantas por K. Ou seja, nos solos de textura médio-arenosa, observou-se maior probabilidade de resposta ao parcelamento do $\mathrm{K}$, como evidenciado nos trabalhos de Lana et al. (2004) e Orlando Filho et al. (1993), ao passo que em solos de textura mais argilosa e com maior CTC o parcelamento pode até mesmo limitar a produtividade 
da cana-de-açúcar (Casagrande et al., 1983), devido ao elevado poder-tampão do solo em K. Esses resultados dão suporte à recomendação de parcelamento da adubação potássica para cana-deaçúcar cultivada em solos de textura arenosa no Estado de São Paulo, conforme Spironello et al. (1997).

No tocante aos atributos tecnológicos, não houve efeito de interação entre os modos de aplicação e as doses. Somente foi observado efeito das doses de K aplicadas unicamente no sulco de plantio para a pureza e os açúcares redutores (AR), que apresentaram regressão quadrática significativa, de modo diretamente proporcional às doses para a pureza e inversamente proporcional para o AR (Quadro 2). Para os atributos brix, pol, fibra e ATR não foi verificada influência das doses e modos de aplicação de K. Esses resultados diferem dos verificados por Lana et al. (2004), que obtiveram efeito linear das doses de K na pol da cana, e por Orlando Filho et al. (1993), que observaram efeito favorável da adubação potássica na pol da cana no quarto corte, colhido precocemente, e no teor de fibra no segundo, quarto e quinto cortes. Entretanto, não foi observado efeito desfavorável do K nos atributos tecnológicos da canade-açúcar, como os obtidos nos trabalhos de Orlando Filho \& Zambello Junior (1980) e Orlando Filho et al. (1990), que observaram decréscimo linear da pol \% cana em função das adubações potássicas, provavelmente devido à absorção de luxo de K pela cana-de-açúcar em seus trabalhos, favorecendo o crescimento vegetativo e prejudicando a maturação da cana-de-açúcar.
As doses de $\mathrm{K}$ promoveram efeito quadrático na produtividade de açúcar tanto para a aplicação única do K no sulco como para a parcelada (Figura 5), devido ao efeito das doses de K na produtividade de colmos, tendo em vista que o K não interferiu na maturação da cana-de-açúcar de modo significativo (Quadro 2).

Os resultados apresentados neste trabalho mostram que o $\mathrm{K}$ desempenha papel importante no crescimento da cana-de-açúcar, na produtividade de colmos e na produtividade de açúcar, especialmente em solos com baixos teores do nutriente. Doses excessivas de $\mathrm{K}$ (superiores a $150 \mathrm{~kg} \mathrm{ha}^{-1}$ de $\mathrm{K}_{2} \mathrm{O}$ ) limitaram o crescimento e a produtividade da canade-açúcar nas condições deste experimento. As doses

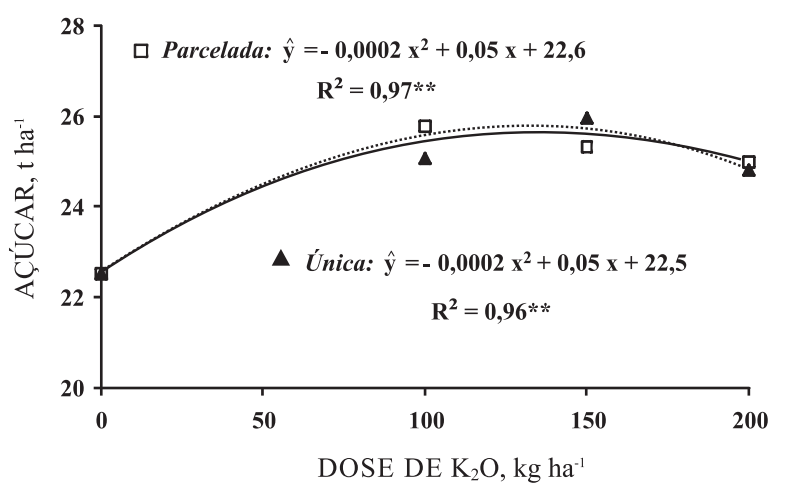

Figura 5. Produtividade de açúcar (pol, em $\mathrm{t} \mathrm{ha}^{-1}$ ), em função dos modos e doses de aplicação de potássio. **: significativo a $1 \%$.

Quadro 2. Atributos tecnológicos da cana-de-açúcar, em função dos modos e doses de aplicação de potássio

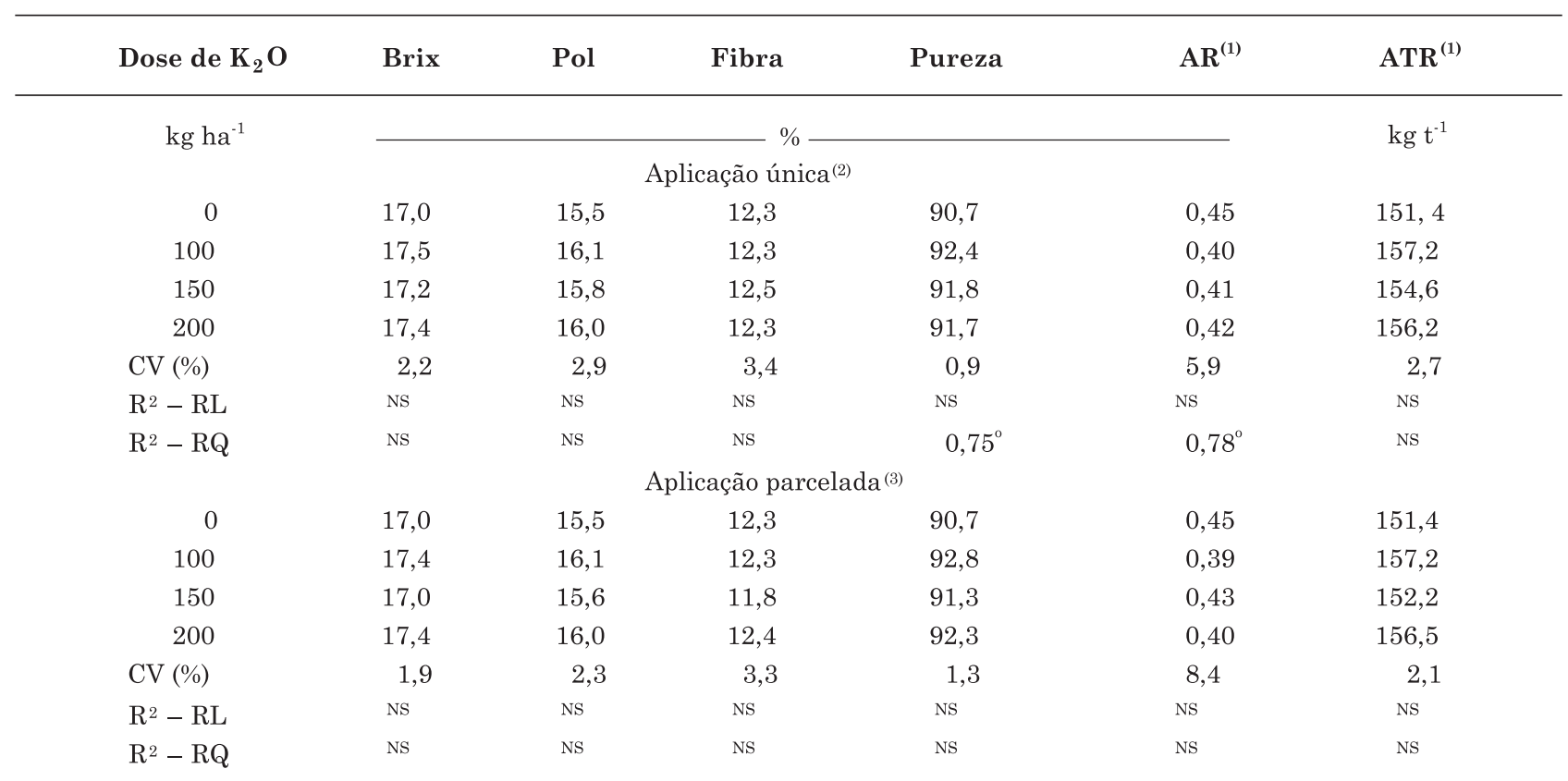

(1) AR: açúcar redutor; ATR: açúcares totais recuperáveis. ${ }^{(2)} 100 \%$ no sulco de plantio. ${ }^{(3)} 50 \%$ no plantio e $50 \%$ em cobertura, aos seis meses após o plantio. ${ }^{\circ} \mathrm{e}^{\mathrm{NS}}$ : significativo a $10 \%$ e não significativo, respectivamente. 
de K mostraram efeito significativo nesses atributos, bastante superior ao efeito isolado do modo de aplicação do fertilizante, uma vez que o efeito favorável do parcelamento da adubação potássica não se mostrou tão claro. Entretanto, deve-se considerar que outros trabalhos da literatura mostraram o efeito favorável do parcelamento da adubação potássica na produtividade da cana-de-açúcar, especialmente em solos de baixa CTC, que apresentam condições favoráveis para a lixiviação desse nutriente.

\section{CONCLUSÕES}

1. As doses de $\mathrm{K}$ favoreceram a altura e o perfilhamento da cana-de-açúcar, tanto para a aplicação única como para a parcelada.

2. Houve efeito significativo das doses de $\mathrm{K}$ na produtividade de colmos e de açúcar até a dose em torno de $160 \mathrm{~kg} \mathrm{ha}^{-1}$ de $\mathrm{K}_{2} \mathrm{O}$, a partir da qual houve decréscimo da produtividade. Por sua vez, não houve diferença significativa entre a aplicação única ou parcelada do fertilizante potássico nesses atributos.

3. A produtividade máxima estimada (cerca de 160 t ha $^{-1}$ de colmos ) pôde ser obtida com a aplicação de de $130 \mathrm{~kg} \mathrm{ha}^{-1}$ de $\mathrm{K}_{2} \mathrm{O}$ na forma parcelada ou $150 \mathrm{~kg} \mathrm{ha}{ }^{-1}$ de $\mathrm{K}_{2} \mathrm{O}$ de uma única vez no plantio.

4. As doses e os modos de aplicação de $\mathrm{K}$ não influenciaram os atributos tecnológicos da cana-deaçúcar.

\section{AGRADECIMENTOS}

Ao Grupo Cosan, por meio do EngenheiroAgrônomo João Américo Beltrame e do Técnico Agrícola Antônio Luis Palhares, pela disponibilização da área e pelo apoio operacional; à Potafos, atual IPNI - International Plant Nutrition Intitute, pelo financiamento do projeto; aos Engenheiros-Agrônomos Fábio Eduardo de Campos Queiroz, Thiago Aristides Quintino e Danilo Barbosa de Oliveira, integrantes do GAPE - Grupo de Apoio à Pesquisa e Extensão, pelo auxílio na condução do experimento; e aos revisores anônimos pelas sugestões para a melhoria do trabalho.

\section{LITERATURA CITADA}

ALBUQUERQUE, G.A.C. \& MARINHO, M.L. Efeito do parcelamento e épocas de adubação da cana-de-açúcar em Alagoas. Brasil Açuc., 10:17-23, 1982.

ALVAREZ, R. \& FREIRE, E.S. Adubação da cana-de-açúcar. VI. Fracionamento da dose de potássio. Bragantia, 21:3143, 1962.
ASSOCIAÇÃO NACIONAL PARA DIFUSÃO DE ADUBOS ANDA. Anuário Estatístico do Setor de Fertilizantes. São Paulo, 2008.

BRASIL. Ministério da Agricultura, Pecuária e Abastecimento. 2009. Anuário Estatístico da Agroenergia. Brasília, 2009. Disponível em: <http://www.agricultura.gov.br>. Acesso em 11 set. 2009.

CASAGRANDE, J.C.; ZAMBELLO JUNIOR, E. \& ORLANDO FILHO, J. Fracionamento da adubação nitrogenada e potássica em cana-planta no Estado de São Paulo. Saccharum, 28:43-48, 1983.

FARONI, C.E. Sistema radicular da cana-de-açúcar e identificação de raízes metabolicamente ativas. Piracicaba, Escola Superior de Agricultura "Luiz de Queiroz", 2004. 68p. (Tese de Mestrado)

FERNANDES, A.C. Cálculos na agroindústria de cana-deaçúcar. 2.ed. Piracicaba, STAB, 2003. 240p.

FRANCO, H.C.J.; CANTARELLA, H.; TRIVELIN, P.C.O.; VITTI, A.C.; OTTO, R.; FARONI, C.E.; SARTORI, R.H. \& TRIVELIN, M.O. Acúmulo de nutrientes pela canaplanta. STAB Açúcar, Álcool Subpr., 26:47-51, 2008.

GHIBERTO, P.J. Lixiviação de nutrientes em um Latossolo cultivado com cana-de-açúcar. Piracicaba, Escola Superior de Agricultura "Luiz de Queiroz", 2009b. 158p. (Tese de Doutorado)

GHIBERTO, P.J.; LIBARDI, P.L.; BRITO, A.S. \& TRIVELIN, P.C.O. Leaching of nutrients from a sugarcane crop growing on an Ultisol in Brazil. Agric. Water Manage., 96:1443-1448, 2009a.

INFORZATO, R. \& ALVAREZ, R. Distribuição do sistema radicular da cana-de-açúcar, variedade Co290, em solo tipo terra-roxa legítima. Bragantia, 16:1-13, 1957.

INSTITUTO BRASILEIRO DE GEOGRAFIA E ESTATÍSTICA - IBGE. Levantamento sistemático da produção agrícola. Disponível em: <http://www.ibge.gov.br/home/estatistica/ indicadores/agropecuaria/lspa/lspa_200908_5.shtm> Acesso em 11 set. 2009.

LANA, R.M.Q.; ZANÃO JÚNIOR, L.A.; KORNDORFER, G.H. \& MACIEL JUNIOR, V.A. Parcelamento da adubação potássica na cana-planta. STAB Açúcar, Álcool Subpr., 23:28-31, 2004.

MALAVOLTA, E.; VITTI, G.C. \& OLIVEIRA, S.A. Avaliação do estado nutricional das plantas. Princípios e aplicações. 2ed. Piracicaba, Potafós, 1997. 319p.

MALAVOLTA, E. Potássio e enxofre nos solos e culturas brasileiras. Piracicaba, Potafos, 1982. (Boletim Técnico, 4)

OLIVEIRA, M.W.; TRIVELIN, P.C.O.; PENATTI, C.P. \& PICCOLO, M.C. Decomposição e liberação de nutrientes da palhada de cana-de-açúcar em campo. Pesq. Agropec. Bras., 34:2359-2362, 1999.

ORLANDO FILHO, J. \& ZAMBELLO JUNIOR, E. Influência da adubação NPK nas qualidades tecnológicas da canaplanta, variedade CB41-76. Brasil Açuc., 96:37-44, 1980. 
ORLANDO FILHO, J.; BOARETTO, A.E. \& GLÓRIA, N.A. Adubação potássica em cana-de-açúcar: I - Efeitos na produtividade agrícola, qualidade da matéria-prima e longevidade. STAB Açúcar, Álcool Subpr., 12:22-26, 1993.

ORLANDO FILHO, J.; SILVA, L.C.F. \& LAVORENTI, N.A. Adubação PK em cana-de-açúcar cultivada em dois espaçamentos de plantio. STAB Açúcar, Álcool Subpr., 8:15-20, 1990.

ORLANDO FILHO, J.; ZAMBELLO JUNIOR, E. \& RODELLA, A.A. Calibração do potássio no solo e recomendação de adubação para cana-de-açúcar. Brasil Açuc., 97:18-24, 1981.

OTTO, R.; TRIVELIN, P.C.O.; FRANCO, H.C.J.; FARONI, C.E \& VITTI, A.C. Root system distribution of sugar cane as related to nitrogen fertilization, evaluated by two methods: Monolith and probes. R. Bras. Ci. Solo, 33:601-611, 2009.

RAIJ, B. van. Fertilidade do solo e adubação. Piracicaba, Potafos, 1991. 343p.

RAIJ, B.van. Calibração de potássio trocável no solo para feijão, algodão e cana-de-açúcar. Ci. Cult., 26:575-579, 1974.

RAIJ, B. van; ANDRADE, J.C.; CANTARELLA, H. \& QUAGGIO, J.A. Análise química para avaliação da fertilidade de solos tropicais. Campinas, Instituto Agronômico de Campinas, 2001. 285p.

REIS JUNIOR, R.A. Probabilidade de resposta da cana-deaçúcar à adubação potássica em razão da relação $\mathrm{K}+\left(\mathrm{Ca}^{2+}\right.$ $\left.+\mathrm{Mg}^{2+}\right)^{-0,5}$ do solo. Pesq. Agropec. Bras., 36:1175-1183, 2001.

RODELLA, A.A.; ZAMBELO JUNIOR, E. \& ORLANDO FILHO, J. Calibração das análises de fósforo e potássio do solo em cana-de-açúcar - $2^{\text {a }}$ aproximação. Saccharum, 28:3942, 1983.

ROSOLEM, C.A. \& NAKAGAWA, J. Residual and annual potassic fertilization for soybeans. Nutr. Cycl. Agroecos., 59:143-149, 2001.
ROSOLEM, C.A.; SANTOS, F.P.; FOLONI, J.S.S. \& CALONEGO, J.C. Potássio no solo em conseqüência da adubação sobre a palha de milheto e chuva simulada. Pesq. Agropec. Bras., 41:1033-1040, 2006.

ROSSETTO, R.; SPIRONELLO, A.; CANTARELLA, H. \& QUAGGIO, J.A. Calagem para a cana-de-açúcar e sua interação com a adubação potássica. Bragantia, 63:105119, 2004.

SOUZA, F.S.; FARINELLI, R. \& ROSOLEM, C.A. Desenvolvimento radicular do algodoeiro em resposta à localização do fertilizante. R. Bras. Ci. Solo, 31:387-392, 2007.

SPARKS, D.L. \& HUANG, P.M. Physical chemistry of soil potassium. In: MUNSON, R.D., ed. Potassium in agriculture. Madison, American Society of Agronomy, 1985. p.201-276.

SPIRONELLO, A.; RAIJ, B.van; PENATTI, C.P.; CANTARELLA, H.; MORELLI, J.L.; ORLANDO FILHO, J.; LANDELL, M.G.A. \& ROSSETO, R. Outras culturas industriais. In: RAIJ, B. van.; CANTARELLA, H.; QUAGGIO, J.A. \& FURLANI, A.M.C., coords. Recomendações de adubação e calagem para o Estado de São Paulo. 2.ed. Campinas, Instituto Agronômico de Campinas, 1997. p.233-239. (Boletim Técnico, 100)

VITTI, G.C. Avaliação e interpretação do enxofre no solo e na planta. Jaboticabal, FUNEP, 1989. 37p.

WERLE, R.; GARCIA, R.A. \& ROSOLEM, C.A. Lixiviação de potássio em função da textura e da disponibilidade do nutriente no solo. R. Bras. Ci. Solo, 32:2297-2305, 2008.

WIETHOLTER, S. Bases teóricas e experimentais de fatores relacionados com a disponibilidade de potássio do solo às plantas usando o trigo como referência. R. Bras. Ci. Solo, 31:1011-1021, 2007. 